Интернет-журнал «Транспортные сооружения» https://t-s.today

Russian journal of transport engineering

2020, №2, Tом 7 / 2020, No 2, Vol 7 https://t-s.today/issue-2-2020.html

URL статьи: https://t-s.today/PDF/06SATS220.pdf

DOI: 10.15862/06SATS220 (http://dx.doi.org/10.15862/06SATS220)

Ссылка для цитирования этой статьи:

Жунев К.О., Мурованный Ю.Н., Яшнов А.Н. Исследование усталостной долговечности сварных соединений железнодорожных пролетных строений // Интернет-журнал «Транспортные сооружения», 2020 №2, https://t-s.today/PDF/06SATS220.pdf (доступ свободный). Загл. с экрана. Яз. рус., англ. DOI: $10.15862 / 06 \mathrm{SATS} 220$

For citation:

Zhunev K.O., Murovannyj Ju.N., Yashnov A.N. (2020). Fatigue life research of welded joints in railway girder. Russian journal of transport engineering, [online] 2(7). Available at: https://t-s.today/PDF/06SATS220.pdf (in Russian). DOI: 10.15862/06SATS220

\title{
УДК 624.014.078.45
}

ГРНТИ 67.03.03

Жунев Кирилл Олегович

ФГБОУ ВО «Сибирский государственный университет путей сообщения», Новосибирск, Россия

Инженер

Аспирант

E-mail: junev.kirill@yandex.ru РИНЦ: https://elibrary.ru/author_profile.asp?id=886253

Мурованный Юрий Николаевич

ФГБОУ ВО «Сибирский государственный университет путей сообщения», Новосибирск, Россия Старший научный сотрудник

E-mail:mura@stu.ru РИНЦ: https://elibrary.ru/author_profile.asp?id=970879

Яшнов Андрей Николаевич ФГБОУ ВО «Сибирский государственный университет путей сообщения», Новосибирск, Россия Заведующий кафедрой «Мосты» Кандидат технических наук, доцент

E-mail: yan@stu.ru РИНЦ: https://elibrary.ru/author_profile.asp?id=490584

\section{Исследование усталостной долговечности сварных соединений железнодорожных пролетных строений}

Аннотация. Прогрессирующее трещинообразование в сварных узлах железнодорожных пролетных строений требует достоверного прогнозирования усталостной долговечности таких конструкций. Было установлено, что наиболее распространены трещины типа Т-9 и Т-10, образующиеся в прикреплениях вертикальных ребер жесткости к стенке балки. Расчет усталостного ресурса таких сварных соединений по существующим нормативным документам показывает завышенные результаты. Для уменьшения погрешности были исследованы особенности работы этих соединений под обращающейся нагрузкой. Контроль напряженнодеформированного состояния осуществляли при помощи малогабаритного автоматизированного тензометрического комплекса «Тензор-МС». Всего было исследовано 13 решетчатых и сплошностенчатых пролетных строений. В результате было установлено, что стенка балки в месте обрыва сварного шва ребра жесткости испытывает изгибные деформации, 
а для расчета долговечности таких соединений используют кривые усталости, полученные при растяжении-сжатии. Для повышения достоверности усталостного расчета были проведены лабораторные испытания на многоцикловую усталость сварных соединений, моделирующих работу элементов с трещинами Т-9, Т-10. Конструкция и материалы лабораторных образцов были назначены аналогично конструкции и материалам главных балок или продольных балок проезжей части пролетных строений. Анализ фактической напряженности под обращающейся нагрузкой позволил выявить необходимые режимы нагружения лабораторных образцов. Всего было испытано 42 лабораторных образца. В результате проведенных испытаний были получены кривые усталости сварных соединений при испытании на изгиб. Полученные экспериментальные данные показывают снижение долговечности соединений на 20-50 \% по сравнению с образцами, испытываемыми на растяжение-сжатие. Кроме того, в результате испытаний были получены зависимости скорости роста усталостных трещин от максимальных напряжений цикла.

Ключевые слова: металлический мост; железнодорожное пролетное строение; сварное соединение; экспериментальное исследование; лабораторные испытания; многоцикловая усталость; кривая усталости; напряженно-деформированное состояние

\section{Введение}

На сети железных дорог России эксплуатируют более 11300 металлических пролетных строений. Половина из этих конструкций изготовлена с применением автоматической сварки и запроектирована под современную нагрузку С14. Из них $20 \%$ имеют повреждения в виде усталостных трещин, образовавшихся в сварных швах металлоконструкций [1]. Для изучения процесса трещинообразования еще в 80-х гг. прошлого века были проведены обследования эксплуатируемых сварных пролетных строений, позволившие составить классификацию типичных трещин и разработать рекомендации по содержанию и усилению пролетных строений с трещинами ${ }^{1}$. Однако детальное изучение этого процесса 30 лет назад не было осуществлено из-за низкой репрезентативности статистики отказов и сложности определения напряженно-деформированного состояния в узлах трещинообразования. В настоящий момент для оценки надежности и долговечности сварных пролетных строений приходится возвращаться к решению этих вопросов, поскольку за прошедшее время была накоплена представительная статистика трещинообразования, а современный уровень развития цифровых технологий и средств измерений позволяет с высокой точностью контролировать уровень напряженного состояния мостовых конструкций на всех этапах жизненного цикла.

Известно, что усталостное разрушение металла является результатом действия переменных нагрузок, величина которых значительно меньше предельной статической нагрузки. Для прогнозирования усталостной долговечности сварных соединений металлических конструкций применяют методические указания ${ }^{2}$. В расчетах используют гипотезу линейного суммирования повреждений [2] и семейство кривых усталости типовых сварных соединений. Кривые усталости отражают зависимость предельного количества циклов до разрушения от максимальных напряжений и коэффициента асимметрии цикла. Применение данных указаний для определения усталостной долговечности сварных соединений пролетных мостов подробно описано в работах [3; 4]. Однако расчетная долговечность сварных швов вертикальных ребер жесткости в местах образования наиболее распространенных трещин Т-9

${ }^{1}$ Указания по осмотру и усилению эксплуатируемых сварных пролетных строений. М.: МПС, 1990. 28 с.

2 РД 50-694-90. Вероятностный метод расчета на усталость сварных конструкций. - М.: Госком. СССР по управлению качеством продукции и стандартов, 1991. - 84 с. 
и Т-10 [5], по кривой усталости 5а, применяемой для расчета таких соединений, получается больше (28-40 лет), чем фактическая долговечность (5-10 лет) [6]. Большая погрешность при определении долговечности может быть связана с использованием кривых усталости не соответствующих фактическому напряженному состоянию элементов пролетных строений.

Данная работа направлена на изучение фактического напряженно-деформированного состояния элементов болто-сварных железнодорожных пролетных строений, подверженных возникновению наиболее распространенных типов трещин, и дополнение семейства кривых усталости типовых соединений для повышения достоверности прогнозирования усталостной долговечности сварных соединений в таких конструкциях.

\section{Методы}

С целью определения фактического напряженно-деформированного состояния элементов, подверженных образованию усталостных трещин типа Т-9 и Т-10, были измерены деформации стенки балки под обращающейся нагрузкой и получены графики изменения напряжений. Для измерений был использован, разработанный сотрудниками СибНИИ мостов (НИЛ «Мосты») СГУПС и применяемый для оценки напряженно-деформированного состояния различных конструкций [7; 8], тензометрический комплекс «Тензор-МС» [9]. Съемные тензометрические датчики устанавливали перпендикулярно наиболее вероятному направлению развития трещин около верхнего и нижнего вырезов ребра жесткости, на расстоянии 20 мм от ребра жесткости. Расположение тензометрических датчиков на стенке балки показано на рис. 1.

a)

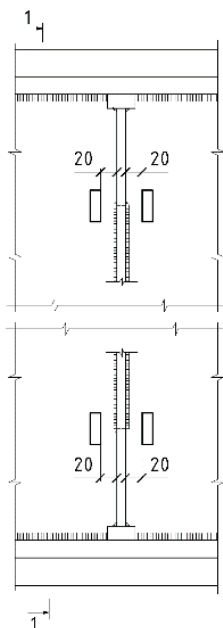

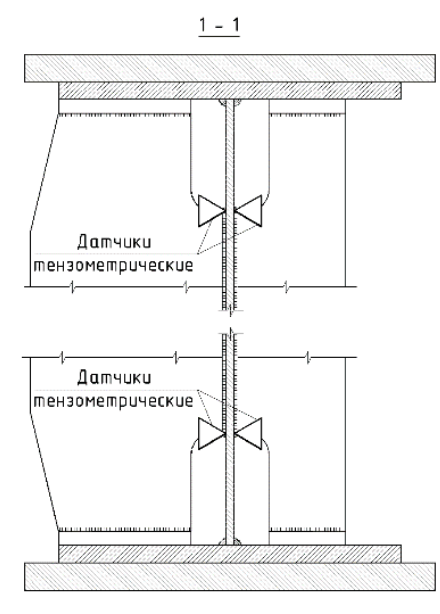

б)

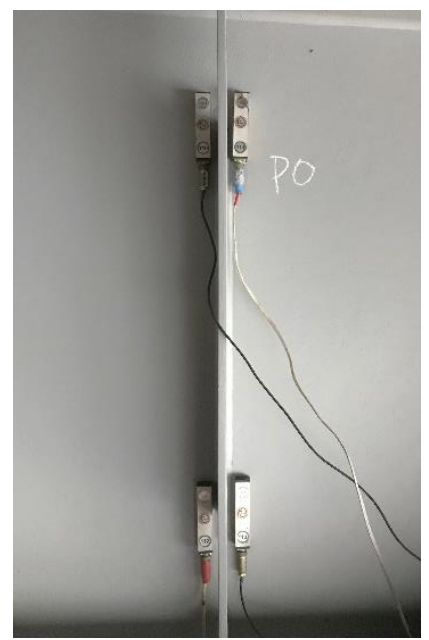

Рисунок 1. Расположение тензометрических датчиков на стенке балки:

$a$-схема расстановки датчиков; б - фактическое расположение датчиков на внешней стороне стенки балки (рисунок/фото авторов)

В качестве объектов исследований были выбраны сплошностенчатые и решетчатые пролетные строения, выполненные по наиболее распространенным типовым проектам (ТП) с различными расчетными длинами $\left(L_{p}\right)$. Таким образом, измерения были проведены в сплошностенчатых пролетных строениях, выполненных по ТП инв. № 821 ( $L_{p}=18,2$ м, $L_{p}=23,0$ м, $L_{p}=33,6$ м); ТП инв. № $563\left(L_{p}=27,0 \mathrm{м}, L_{p}=33,6\right.$ м); и решетчатых пролетных строениях, выполненных по ТП инв. № $690\left(L_{p}=44,0\right.$ м, $L_{p}=55,0$ м, $L_{p}=66,0$ м, $L_{p}=87,5$ м). В процессе обследований сплошностенчатых пролетных строений измерения производили у всех вертикальных ребер жесткости главных балок. При обследовании решетчатых пролетных строений измерения производили у вертикальных ребер жесткости продольных балок проезжей части в первой панели. 
С целью получения кривых усталости рассматриваемых соединений натурные исследования были дополнены лабораторными испытаниями на усталость образцов, моделирующих работу сварных узлов реальных конструкций. В качестве лабораторных образцов использовали консольно-закрепленный горизонтально расположенный металлический лист, к которому сверху и снизу были приварены ребра жесткости. Лабораторные образцы были изготовлены из стали $15 \mathrm{XCHД} \mathrm{обычного} \mathrm{исполнения.}$ Геометрические характеристики образцов были подобны соединениям в реальных конструкциях: толщина ребер жесткости - 10 мм, толщина горизонтального листа -12 мм, ширина ребер жесткости - 120 мм, катет шва -8 мм. Сварные швы были выполнены полуавтоматической сваркой. Принятая конструкция образцов позволила смоделировать работу стенки балки в месте обрыва сварного шва прикрепления вертикального ребра жесткости.

Для создания, изменяющихся по гармоническому закону, изгибных деформаций горизонтального листа использовали вибродвигатель, прикрепленный к свободному концу образца. Величину средних напряжений цикла задавали грузом, подвешеным к свободному концу образца. Амплитуду колебаний изменяли при помощи частотного преобразователя, подключенного к вибродвигателю, а ее величину контролировали при помощи тензодатчика, установленного около обрыва сварного шва ребра жесткости на расстоянии 20 мм. Схема и фотография установки для испытаний приведены на рис. 2.

a)

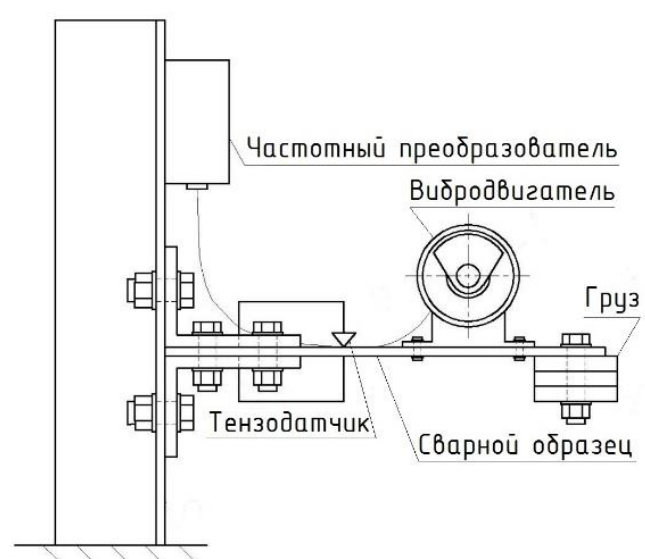

б)

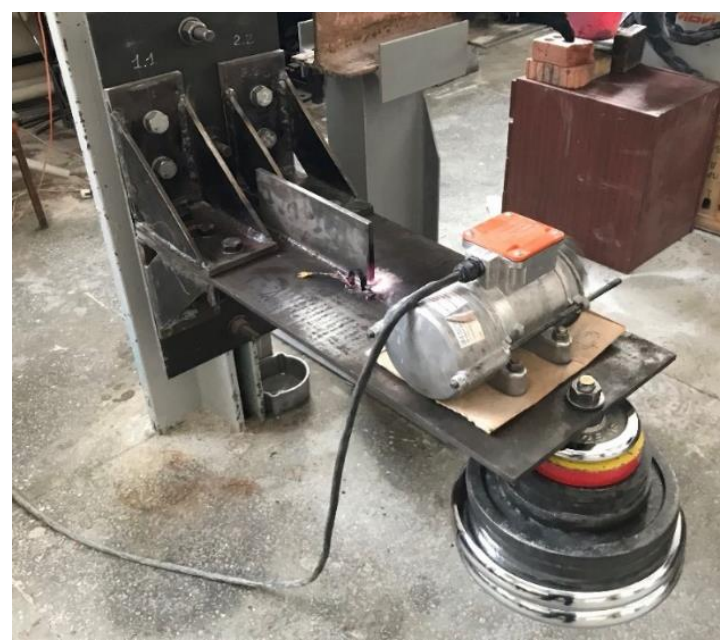

Рисунок 2. Установка для испьтания на усталость сварных образиов при изгибе: а -схема установки для испьтаний; б - фотография установки для испытаний (рисунок/фото авторов)

Базу испытаний для определения предела выносливости назначили равной 4 млн циклов. В качестве критерия разрушения образца для построения кривых усталости было принято образование усталостной трещины длиной 3-5 мм в основном металле. Для контроля состояния сварного шва в процессе испытаний применяли капиллярный и тензометрический методы неразрушающего контроля. В начале испытания каждого образца записывали контрольный график изменения напряжений (тензограмму) в месте обрыва сварного шва без трещины. В дальнейшем измерения производили с периодичностью 150-250 тыс. циклов. Момент образования трещины и дальнейшее изменение напряженно-деформированного состояния трещины фиксировали по показаниям тензометрических датчиков, размер трещины определяли при помощи метода капиллярной дефектоскопии. В процессе испытаний помимо фиксации количества циклов на различных этапах трещинообразования определяли скорость роста трещины до величины 15-25 мм. 


\section{Результаты}

Измерения деформаций в стенках балок были выполнены у более чем 170 ребер жесткости в 13 пролетных строениях, эксплуатируемых на различных участках Транссибирской магистрали с различными видами мостового полотна (плиты безбалластного мостового полотна, деревянный мостовой брус) под обращающимися поездами с разной осевой нагрузкой. Результаты измерений показали, что при проходе подвижной нагрузки стенка балки в месте обрыва вертикального ребра жесткости испытывает поперечный изгиб, при этом диапазон максимальных напряжений цикла в стенке балки на расстоянии 20 мм от ребра жесткости изменяется от 200 до 600 кгс/см². Наибольшие значения напряжений были зафиксированы у верхних концов ребер жесткости, имеющих неплотное примыкание к поясам балок с зазором более 1 мм. Пример записанной тензограммы в стенке балки у вертикального ребра жесткости при проходе грузового поезда, показан на рис. 3.



Рисунок 3. Тензограмма напряжений в стенке продольной балки у верхнего конца сварного шва вертикального ребра жесткости решетчатого пролетного строения при проходе грузового поезда (рисунок авторов)

Анализ полученных результатов натурных испытаний показал, что наиболее часто в стенках балок действуют циклы напряжений с коэффициентом асимметрии от $-0,4$ до +0,4. Опираясь на полученные данные в результате натурных измерений в рамках лабораторных исследований были проведены испытания образцов в диапазоне максимальных номинальных напряжений цикла $\left(\sigma_{\max }\right)$ от 500 до 1100 кгс/см² при трех коэффициентах асимметрии цикла $(\rho):-0,3 ; 0,0 ;+0,3$. На каждом уровне напряжений испытывали от 1 до 5 образцов в зависимости от разброса значений долговечности. Всего было испытано 42 сварных соединения. Результаты испытаний приведены в виде кривых усталости и аппроксимирующих функций на рис. 4. В качестве аппроксимирующих кривых были рассмотрены показательная, логарифмическая и степенная функции. Качество аппроксимации оценивали по коэффициенту детерминации $\left(R^{2}\right)$ [10]. Наиболее качественную аппроксимацию результатов для каждой серии испытаний с постоянным коэффициентом асимметрии циклов напряжений дает степенная кривая вида:

$$
N=\left(\frac{C}{\sigma_{\max }}\right)^{m}
$$


где $C, m$ - эмпирические коэффициенты кривой усталости; $\sigma$ - максимальные

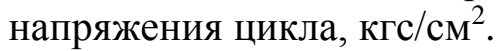

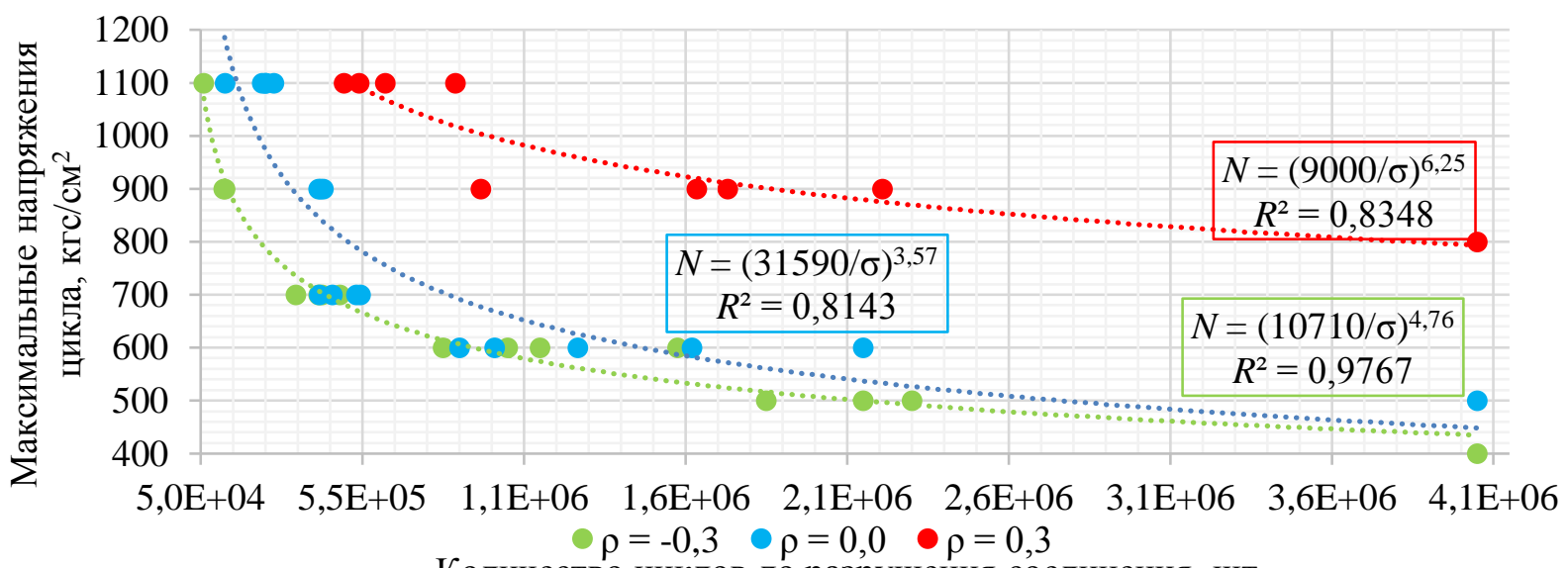

Количество циклов до разрушения соединения, шт.

Рисунок 4. Кривые усталости, полученные в результате испытания сварных соединений при действии изгибающего момента (рисунок авторов)

Полученные кривые усталости отражают зависимость количества циклов до образования трещины длиной 3-5 мм от номинальных напряжений около сварного шва ребра жесткости с вероятностью 0,50. Пределы выносливости в зависимости от коэффициента асимметрии цикла получены равными: $\sigma_{0,3}=850$ кгс $/ \mathrm{cm}^{2}, \sigma_{0}=550$ кгс $/ \mathrm{cm}^{2}, \sigma_{-0,3}=450$ кгс/ $\mathrm{cm}^{2}$.

Сравнение начальных (контрольных) тензограмм с тензограммами, полученными при дальнейшем испытании образцов, показывает, что момент образования усталостной трещины связан с резким увеличением деформаций на 10-15\%. Последующее развитие трещины приводит к плавному увеличению деформаций. На момент развития трещины до размеров, соответствующих критерию разрушения (3-5 мм), деформации конструкции увеличиваются на 30-35 \% по сравнению с первоначальными в исправной конструкции. Примеры сравнения тензограмм на различных этапах испытания образов приведены на рис. 5.

a)

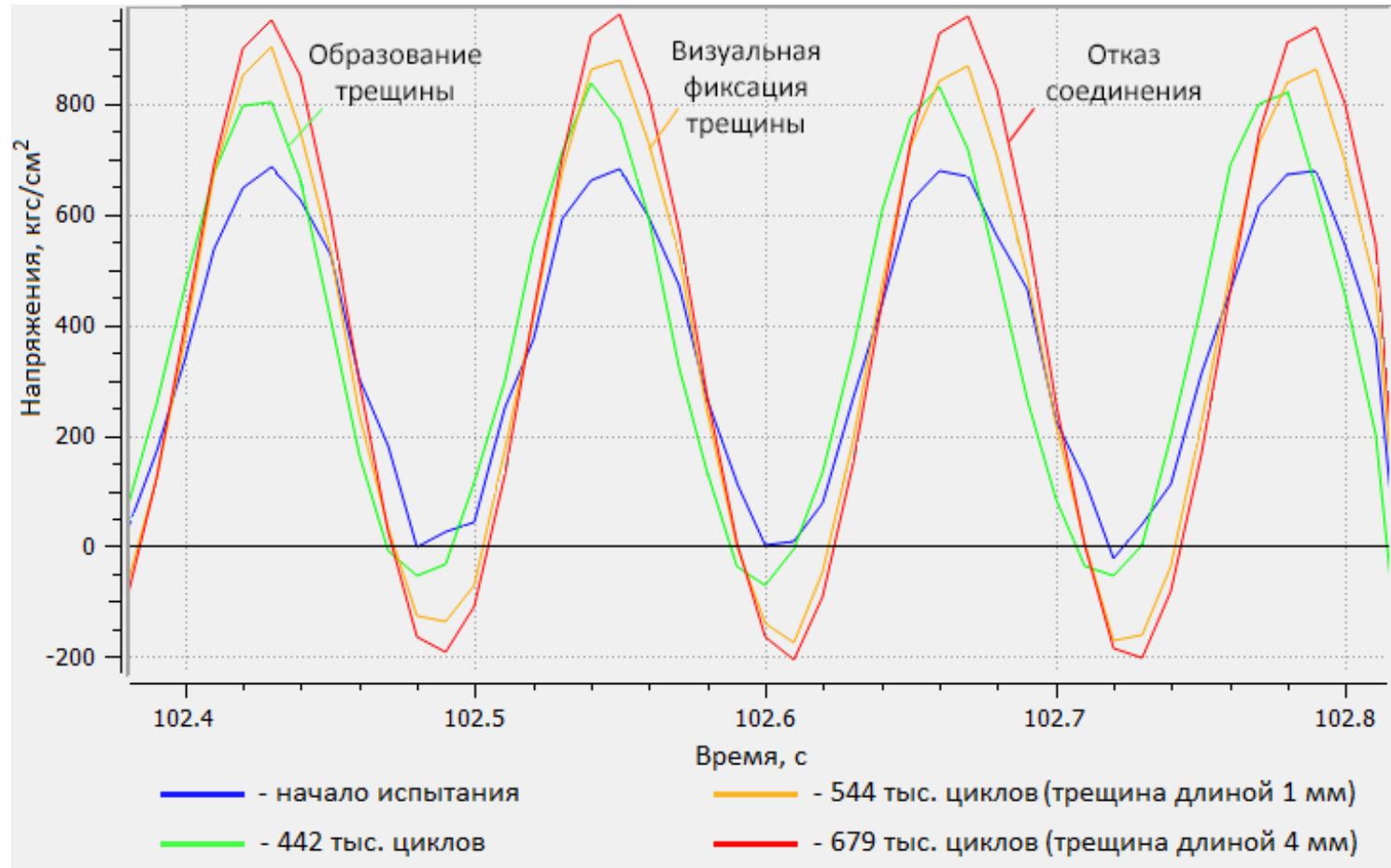


б)

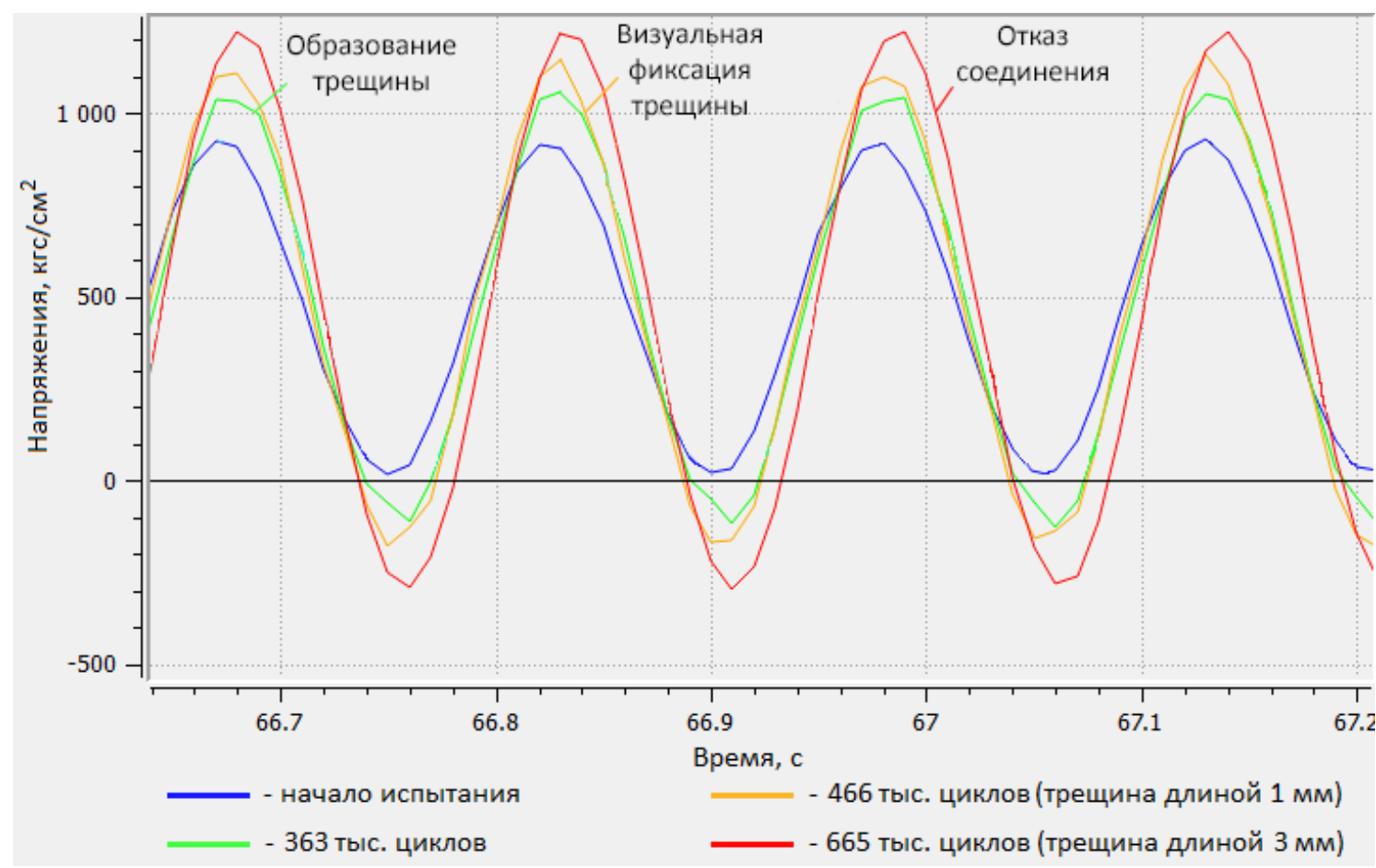

Рисунок 5. Тензограммы напряжений в лабораторных образцах около обрыва

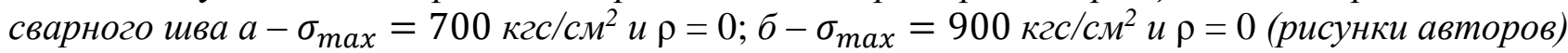

Контроль напряженно-деформированного состояния позволил выявить трещины в среднем на 200 тыс. циклов раньше, чем при использовании капиллярной дефектоскопии. Это объясняется тем, что капиллярный метод неразрушающего контроля имеет более высокий порог чувствительности, чем тензометрический, и визуально зафиксировать трещину удается только при ее подрастании до 0,7-1,0 мм. Таким образом, тензометрический метод контроля может быть эффективно применен для выявления наличия трещин еще на этапе их зарождения.

Результаты измерения длин трещин в зависимости от количества циклов, подсчитываемых с момента образования трещин, для серий образцов с различными амплитудами напряжений цикла $(\Delta \sigma)$ представлены на рис. 6.

a)

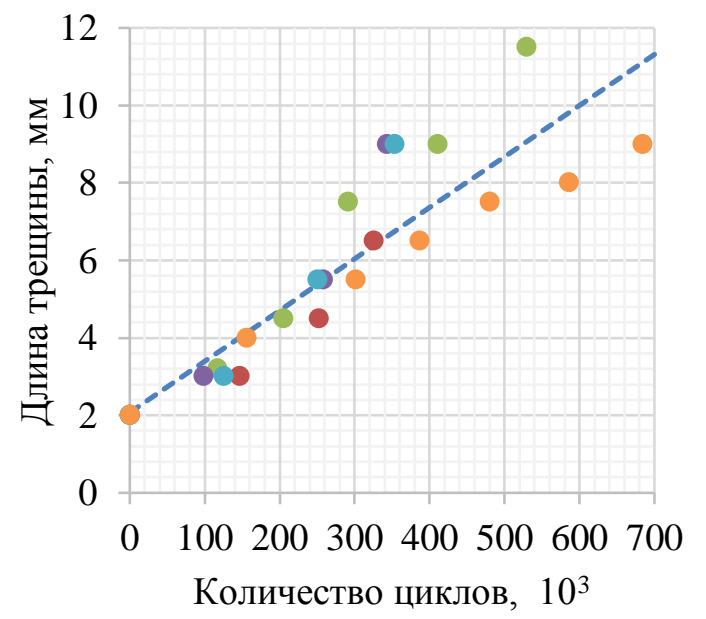

б)

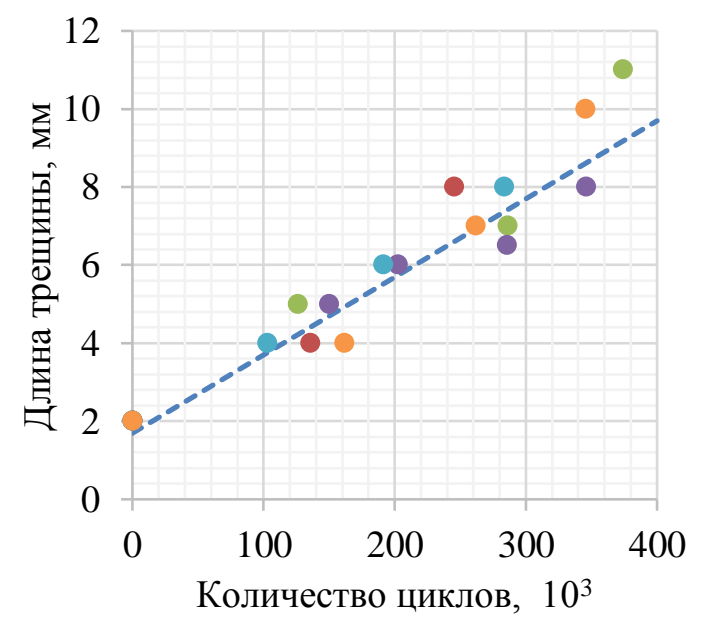


в)

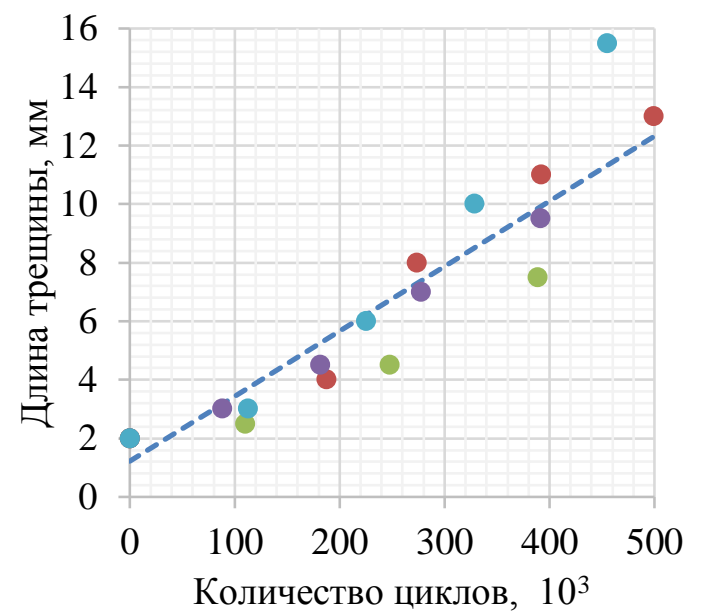

2)

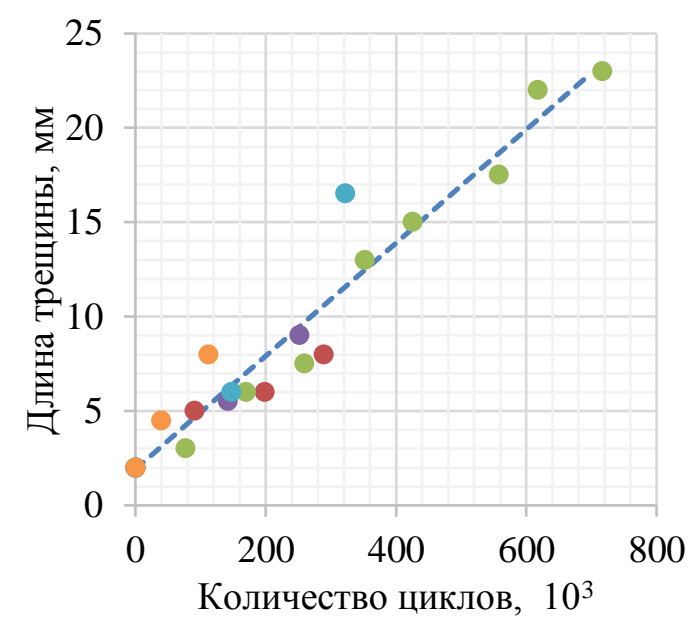

d)

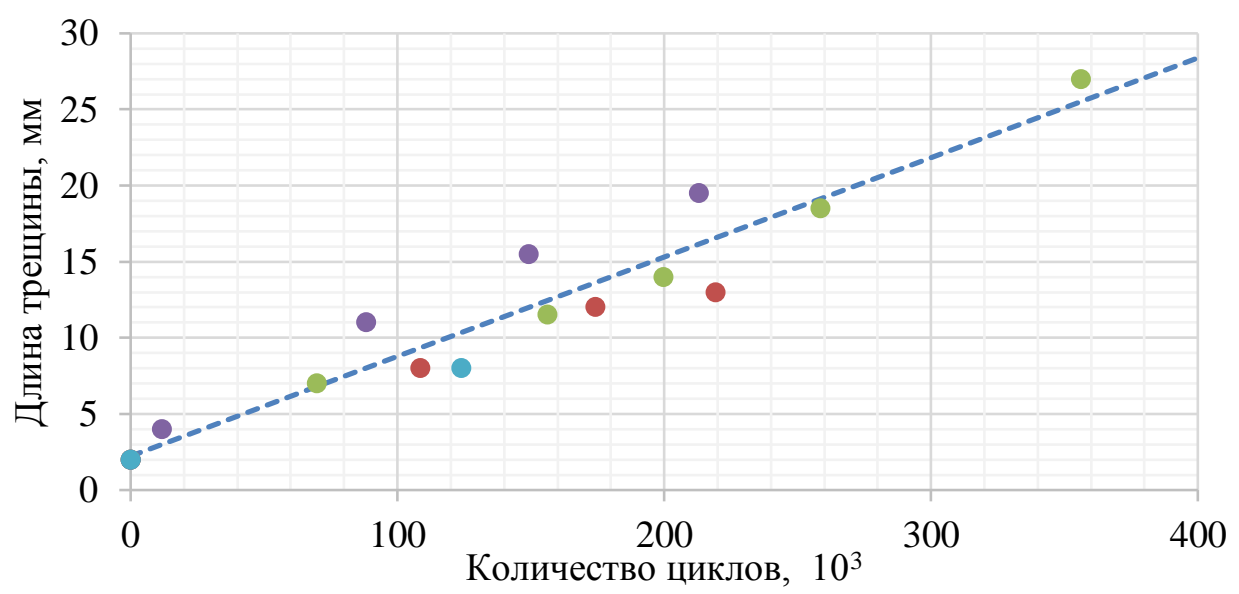

Рисунок 6. Скорость роста усталостных трещин в зависимости от амплитуды напряжений ичикла: $а$ - серия образцов при $\Delta \sigma=600 \kappa 2 c / \mathrm{cm}^{2} ; \sigma-$ серия образиов при $\Delta \sigma=700$

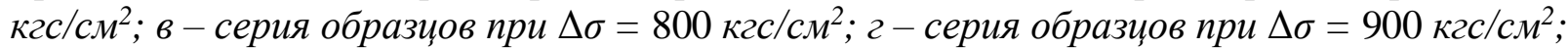

$$
\partial \text { - серия образцов при } \Delta \sigma=1100 \kappa г c / \text { м }^{2} \text { (рисунки авторов) }
$$

Анализ полученных данных позволил выявить зависимость скорости роста усталостных трещин от амплитуды напряжений цикла. На рис. 7 приведен график, отражающий среднее количество циклов, необходимое для приращения усталостной трещины на 1 мм, в зависимости от амплитуды напряжений.

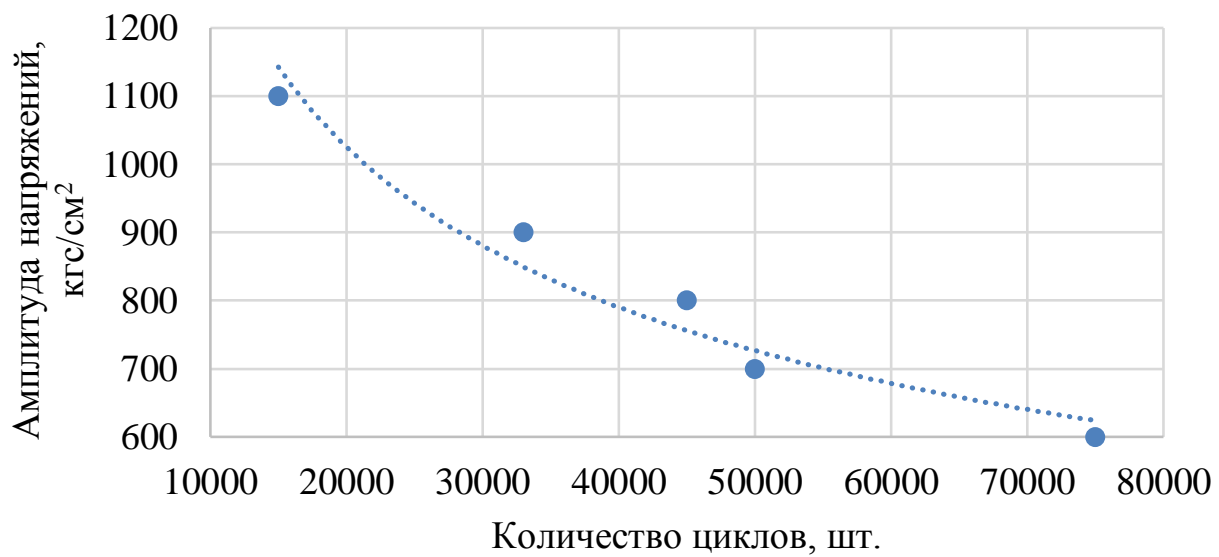

Рисунок 7. Среднее количество изиклов, необходимое для приращения усталостной трещины на 1 мм в зависимости от амплитуды напряжений (рисунки авторов) 


\section{Обсуждение}

Наблюдения за образованием и развитием трещин в процессе лабораторных испытаний позволили установить, что зарождение трещины происходит на преимущественно растянутой (верхней) поверхности образца в торце сварного шва по зоне его сплавления с основным металлом. В дальнейшем трещина распространяется в основной металл, являясь поверхностной. Сквозное поражение листа металла усталостной трещиной происходит при достижении трещиной длины равной толщине листа. В подавляющем большинстве случаев развитие трещины происходит перпендикулярно ребру жесткости по плоскостям максимальных нормальных напряжений [11] и показано на рис. 8.


Рисунок 8. Характерные усталостные трещины около обрыва сварного шва ребра жесткости (фото авторов)

Для определения расчетной зависимости усталостной долговечности лабораторных образцов от определяющих факторов был проведен корреляционный анализ результатов испытаний с применением коэффициента корреляции Пирсона [10]. В качестве зависимой переменной было выбрано количество циклов до разрушения сварного соединения, а в качестве независимых: коэффициент асимметрии цикла, максимальное напряжение и амплитуда напряжений. В результате было установлено, что для описания расчетной зависимости долговечности следует использовать максимальные напряжения цикла и коэффициент асимметрии, коэффициенты корреляции которых $-0,72$ и 0,70 соответственно. Третья переменная - амплитуда напряжений является производной от максимальных напряжений и коэффициента асимметрии, что приводит к снижению коэффициентов корреляции регрессионной модели при одновременном учете трех параметров. В качестве уравнения для описания расчетной зависимости долговечности сварного соединения от максимальных напряжений и коэффициента асимметрии цикла была принята также степенная кривая:

$$
N=\left(\frac{17900}{\sigma_{\max }(1-\rho)}\right)^{4,35} .
$$

На рис. 9 изображены графики полученной экспериментальной кривой усталости и кривой усталости типа 5а, полученной в результате испытаний аналогичных сварных соединений при действии растяжения-сжатия ${ }^{3}$.

${ }^{3}$ РД 50-694-90. Вероятностный метод расчета на усталость сварных конструкций. - М.: Госком. СССР по управлению качеством продукции и стандартов, 1991. - 84 с. 


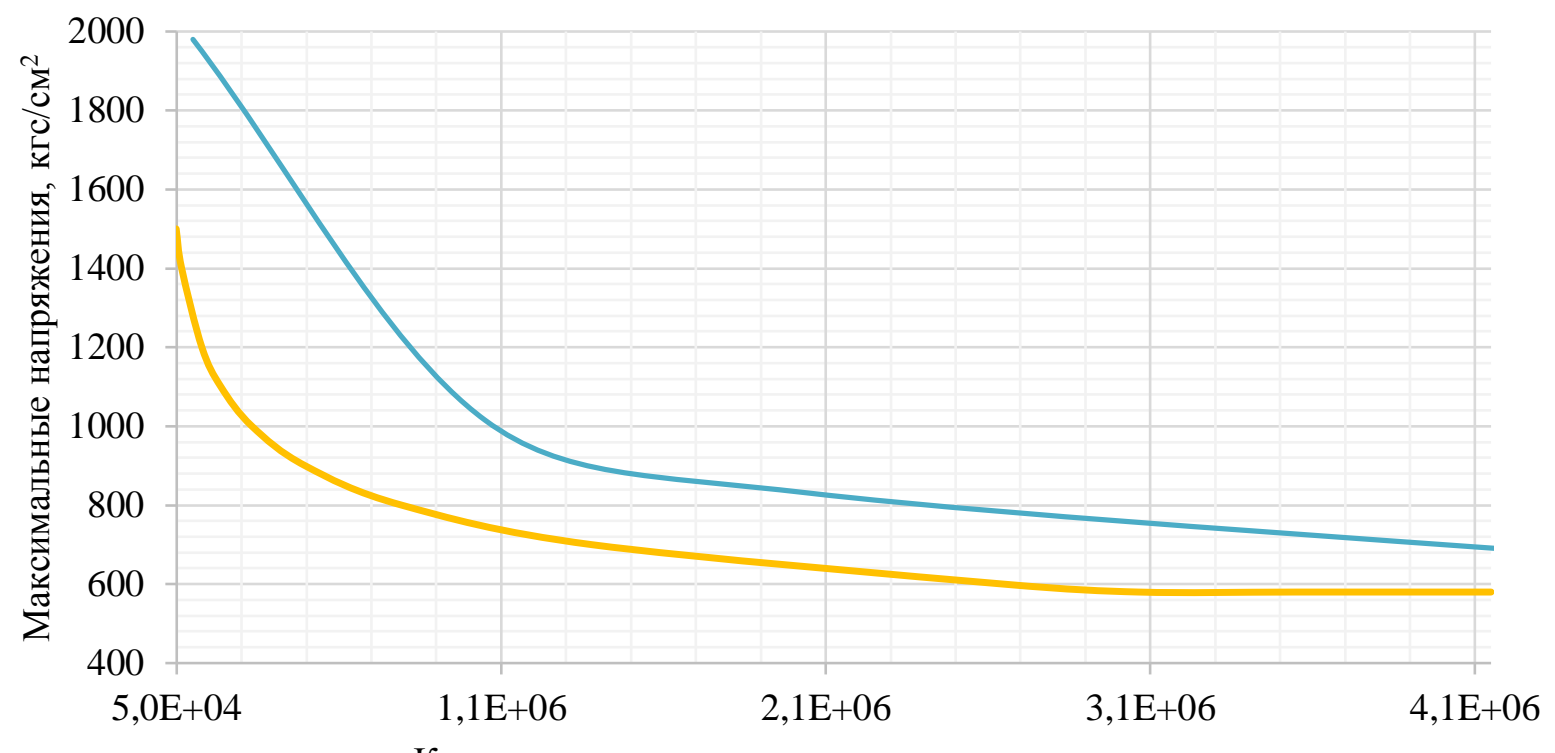

Количество циклов до разрушения соединения, шт.

— Экспериментальная кривая усталости — — Кривая усталости $5 \mathrm{a}$

Рисунок 9. Кривые усталости сварных образцов, испытанных при действии изгибающего момента и растяжения-сжатия при отнулевом цикле напряжений (рисунок авторов)

Анализ кривых усталости показывает, что долговечность лабораторных образцов при испытаниях на изгиб снизилась на 20-50\% по сравнению с долговечностью образцов, испытываемых на растяжение-сжатие. Предел выносливости также уменьшился с 680 кгс/см ${ }^{2}$ до 580 кгс/см². В целом, полученные результаты хорошо согласуется с другими исследованиями усталостной долговечности [12; 13].

В результате проведенного эксперимента семейство кривых усталости типовых соединений было дополнено данными о долговечности образцов, находящихся в напряженнодеформированном состоянии, соответствующем фактическому напряженнодеформированному состоянию элементов болто-сварных пролетных строений. Таким образом, применение полученных кривых усталости позволит увеличить достоверность прогнозирования усталостной долговечности сварных соединений в металлических пролетных строениях.

\section{ЛИТЕРАТУРА}

1. Бокарев С.А., Жунев К.О., Усольцев А.М. Обеспечение пропуска тяжеловесных поездов по металлическим мостам // Путь и путевое хозяйство. 2019. №4. С. 2628.

2. Серенсен С.В. Усталость материалов и элементов конструкций. Избр. труды в 3х томах. Киев: Наукова думка, 1985. Т.2. 256 с.

3. Феоктистова Е.П. Оценка остаточного усталостного ресурса металлических балок сталежелезобетонных пролетных строений автодорожных мостов // Интернет-журнал «Транспортные сооружения», 2019 №3, https://ts.today/PDF/15SATS319.pdf (доступ свободный). Загл. с экрана. Яз. рус., англ. DOI: $10.15862 / 15 S A T S 319$. 
4. Бокарев С.А., Жунев К.О. Особенности и перспективы оценки остаточного ресурса сварных металлических пролетных строений железнодорожных мостов // Вестник Сибирского государственного университета путей сообщения. 2017. №40. С. 30-35.

5. Жунев К.О. Обследование трещиноопасных узлов в болто-сварных пролетных строениях // Сборник материалов IX научно-практической конференции «Обследование зданий и сооружений: проблемы и пути их решения». 2018. С. 6270.

6. Михеев Г.В., Лысиков Н.Н., Погорелов Д.Ю., Круговова Е.А., Кирьян В.И., Мальгин М.Г. Расчет динамической нагруженности и усталостной долговечности железнодорожных мостов методами компьютерного моделирования // Вісник Східноукраїнського національного університету імені Володимира Даля. 2013. №18. C. 184-191.

7. Снежков И.И., Кузьменков П.Ю. Пример применения измерительного комплекса «ТЕНЗОР МС» в мостостроении // Сборник трудов Всероссийской научнотехнической конференции с международным участием «Приборы и методы измерений, контроля качества и диагностики в промышленности и на транспорте». Омск: Изд-во ОмИИТ. 2013. С. 101-105.

8. Яшнов А.Н., Снежков И.И. Опыт диагностики искусственных сооружений методом малых воздействий // Интернет-журнал «Транспортные сооружения», 2019 №3, https://t-s.today/PDF/23SATS319.pdf (доступ свободный). Загл. с экрана. Яз. рус., англ. DOI: 10.15862/23SATS319.

9. Бокарев С.А., Яшнов А.Н., Снежков И.И., Слюсарь А.В. Малогабаритные автоматизированные системы для диагностики ИССО // Путь и путевое хозяйство. 2007. №9. С. 25-26.

10. Гайдышев И.П. Анализ и обработка данных: специальный справочник. СПб: Питер, 2001. 752 с.

11. Николаева Е.А. Основы механики разрушения: учебное пособие. Пермь: Изд-во Пермского гос. тех. ун-та, 2010. - 103 с.

12. Fisher J.W., Yuceoglu U. A survey of localized cracking in steel breedges. Bethlehem: Fritz Engineering Laboratory Report, 1981. 334 p.

13. Bouteta P., Hildb F., Lefebvre F. Probabilistic prediction of fatigue life of cracked parts: linear elastic fracture mechanics based approach // Procedia engineering. 2013. Vol. 66. Pp. 343-353. 
Zhunev Kirill Olegovich

Siberian transport university, Novosibirsk, Russia E-mail: junev.kirill@yandex.ru

Murovannyj Jurij Nikolaevich Siberian transport university, Novosibirsk, Russia E-mail: mura@stu.ru

Yashnov Andrey Nikolaevich

Siberian transport university, Novosibirsk, Russia E-mail: yan@stu.ru

\title{
Fatigue life research of welded joints in railway girder
}

\begin{abstract}
Progressive crack formation in welded joints of railway girders requires a reliable prediction of the fatigue life. It was found that the most common fatigue cracks are T-9 and T-10, which are formed in welded joints of vertical stiffeners to the beam web. The service life calculation of such joints, according to guideline, shows overestimated results. To reduce the error, the operational features of these joints were investigated under a moving loads. Stress-strain monitoring was carried out with the help of a small-sized automated tensometric complex "Tensor-MS". In total, 13 trussed and solid-web girders were investigated. As a result, it was found that the beam web near the welded ends of stiffeners subjected to bending deformations, but fatigue curves, obtained under tensilecompressive, are used to calculate the durability of such joints. To increase the reliability of fatigue calculation, laboratory tests were carried out for a high-cycle fatigue of welded specimens, simulating joints with T-9, T-10 cracks. The design and materials of laboratory specimens were assigned similarly to that of the main beams or the floor beams. Analysis of the actual stresses under the moving load revealed the necessary loading conditions for laboratory specimens. Totally, 42 laboratory samples were tested for bending. As a result of the tests, fatigue curves of welded joints were obtained. The results show a decrease in the joints durability by 20-50\% in comparison with the samples tested in tensile-compressive. In addition, as a result of the tests, the dependences of the fatigue cracks growth rate on the maximum cycle stresses were obtained.
\end{abstract}

Keywords: metal bridge; railway girder; welded joint; experimental research; laboratory test; high-cycle fatigue; fatigue curve; stress-strain state

\section{REFERENCES}

1. Bokarev S.A., Zhunev K.O., Usol'tsev A.M. (2019). Passage of heavy trains on metal bridges. Path and track facilities, 4, pp. 26-28 (in Russian).

2. Serensen S.V. (1985). Ustalost' materialov i ehlementov konstruktsiy. Izbrannye trudy $\mathrm{v} 3$-kh tomakh. Tom 2. [Fatigue of materials and structural elements. Selected works in 3 volumes. Volume 2.] Kiev: Scientific opinion, p. 256.

3. Feoktistova E.P. (2019). Assessment of residual fatigue life of metal beam of reinforced concrete superstructures of road bridges. Russian journal of transport engineering, [online] 3(6). Available at: https://t-s.today/PDF/15SATS319.pdf (in Russian). DOI: 10.15862/15SATS319.

4. Bokarev S.A., Zhunev K.O. (2017). Features and prospects of assessing the residual resource of welded metal spans of railway bridges. Bulletin of the Siberian State University of Railway Engineering, 40, pp. 30-35 (in Russian). 
5. Zhunev K.O. (2018). Obsledovanie treshchinoopasnykh uzlov v bolto-svarnykh proletnykh stroeniyakh. [Examination of crack joints in bolt-welded spans.] pp. 62-70.

6. Mikheev G.V., Lysikov N.N., Pogorelov D.Yu., Krugovova E.A., Kir'yan V.I., Mal'gin M.G. (2013). Calculation of dynamic loading and fatigue life of railway bridges by computer modeling methods. Bulletin of the Volodymyr Dahl East Ukrainian National University, 18, pp. 184-191 (in Russian).

7. Snezhkov I.I., Kuz'menkov P.Yu. (2013). Primer primeneniya izmeritel'nogo kompleksa «TENZOR MS» V mostostroenii. [An example of the use of the measuring complex "TENSOR MS" in bridge building.] Omsk: Publishing House of the Omsk Institute of Railway Engineers, pp. 101-105.

8. Yashnov A.N., Snejkov I.I. (2019). Experience of diagnostics of engineering structures by the method of small impacts. Russian journal of transport engineering, [online] 3(6). Available at: https://t-s.today/PDF/23SATS319.pdf (in Russian). DOI: 10.15862/23SATS319.

9. Bokarev S.A., Yashnov A.N., Snezhkov I.I., Slyusar A.V. (2007). Small-sized automated systems for the diagnosis of ISSO. Path and track facilities, 9, pp. 25-26 (in Russian).

10. Gaydyshev I.P. (2001). Analiz i obrabotka dannykh: spetsial'nyy spravochnik. [Data Analysis and Processing: Special Reference.] Saint Petersburg: Peter, p. 752.

11. Nikolaeva E.A. (2010). Osnovy mekhaniki razrusheniya. [Fundamentals of fracture mechanics.] Perm: Publishing house Perm State Technical University, p. 103.

12. Fisher J.W., Yuceoglu U. (1981). A survey of localized cracking in steel breedges. Bethlehem: Fritz Engineering Laboratory Report, p. 334.

13. Bouteta P., Hildb F., Lefebvre F. (2013). Probabilistic prediction of fatigue life of cracked parts: linear elastic fracture mechanics based approach. Procedia engineering, (66), pp. 343-353. 